\title{
Endometrial Hyperplasia as a Cause of Secondary Postpartum Hemorrhage in a Post Caesarean Section Patient
}

\author{
Charissa Goh ${ }^{\mathrm{a}, \mathrm{d}}$, Manisha Mathur ${ }^{\mathrm{a}}$, Soo Kim Lim-Tan ${ }^{\mathrm{b}}$, Yong Kuei Lim ${ }^{\mathrm{c}}$
}

\begin{abstract}
There are multiple causes of prolonged and persistent postpartum bleeding. The common etiologies include uterine atony, endometritis and retained products of conception. Uncommon causes described in literature include uterine artery pseudoaneurysm, placental site nodule and uterine scar dehiscence. Endometrial hyperplasia causing persistent per vaginal bleeding postpartum has yet to be reported in literature. The rarity of this condition may be attributed to the underlying pathogenesis. Endometrial hyperplasia is caused by unopposed estrogen and it is well established that pregnancy decreases the risk of endometrial hyperplasia. We present a case report of a 42-year-old lady found to have complex endometrial hyperplasia during evaluation for persistent per vaginal bleeding 3 months post Caesarean section.
\end{abstract}

Keywords: Postpartum endometrial hyperplasia; Secondary postpartum hemorrhage

\section{Introduction}

Secondary postpartum hemorrhage (PPH) is defined as any significant bleeding from the birth canal between $24 \mathrm{~h}$ and 12 weeks postnatal [1]. Boyd et al [1] reported an incidence of $0.2 \%$ of secondary PPH amongst women delivered in two hospitals in the United States and re-admitted with a diagnosis of secondary PPH. However, the true frequency of secondary PPH may be difficult to estimate as many of the postpartum patients are discharged to primary care.

\footnotetext{
Manuscript submitted April 16, 2018, accepted May 9, 2018

aDepartment of Obstetrics and Gynecology, KK Women's and Children's Hospital, Singapore

bDepartment of Pathology, KK Women's and Children's Hospital, Singapore 'Department of Gynecologic Oncology, KK Women's and Children's Hospital, Singapore

dCorresponding Author: Charissa Goh, KK Women's and Children's Hospital, 100 Bukit Timah Road, 229899, Singapore.

Email: charissa.goh@mohh.com.sg
}

doi: https://doi.org/10.14740/jmc3064w
There are multiple causes of secondary postpartum bleeding. The common causes include uterine atony, endometritis and retained products of conception [2-4]. Uncommon etiologies described in literature include uterine artery pseudoaneurysm, placental site nodule, idiopathic subinvolution of the uteroplacental vessels, congenital coagulopathy and uterine scar dehiscence [2-12]. Malignant changes including carcinoma of the cervix, uterus or choriocarcinoma can also be included amongst rare causes of secondary PPH $[13,14]$. Leunen et al [14] report a case of a 28-year-old lady presenting with secondary PPH who was later diagnosed with endometrial stromal sarcoma. There is also a case report on postpartum endometrial hyperplasia in diabetic women with history of stilbesterol exposure during pregnancy [15]. However, as there was no control group in the study, a direct causal relationship between stilbesterol use and postpartum endometrial hyperplasia cannot be established. However, endometrial hyperplasia in women with no prior stilbesterol exposure causing persistent per vaginal bleeding postpartum has not yet to be reported in literature, to the best of our knowledge.

\section{Case Report}

\section{Case presentation}

A 42-year-old (gravida 3 para 2) woman underwent an uncomplicated emergency lower segment Caesarean section at 37 weeks gestation for mild pre-eclampsia and history of two prior Caesarean sections. She had no significant past medical history of note. Her pregnancy thus far had been uncomplicated with no history of an early or a late onset antepartum bleed. Preoperatively, a prophylactic dose of the first-generation cephalosporin was administered by intravenous route as routine. In the early postoperative period, she experienced primary PPH estimated at just over $500 \mathrm{~mL}$ that resolved with oxytocin administration and a uterine massage.

Her preoperative hemoglobin was $12.7 \mathrm{~g} / \mathrm{dL}$. In the postoperative period her hemoglobin level was $11.0 \mathrm{~g} / \mathrm{dL}$. The coagulation profiles preoperatively and postoperatively were also within normal limits. The lady was discharged home well on the day 3 postpartum.

She was first reviewed in clinic at 7 weeks postpartum, with complaint of persistent per vaginal spotting. She was 


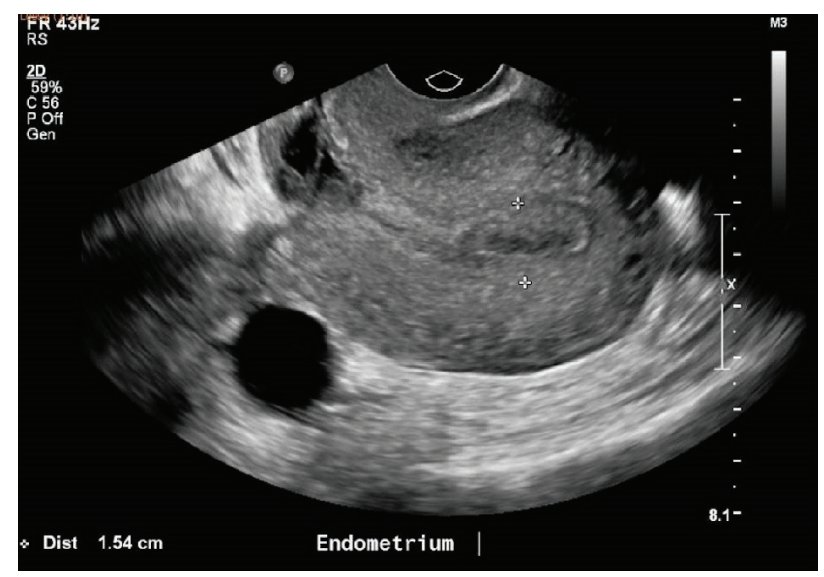

Figure 1. Ultrasound pelvis at 9 weeks postpartum showing an endometrium thickness of $15 \mathrm{~mm}$.

treated empirically with oral antibiotics for presumptive endometritis.

The lady attended follow-up at 9 weeks postpartum. She had stopped breast-feeding but continued to complain of persistent spotting despite the course of antibiotics. Her clinical examination was unremarkable. An ultrasound pelvis was arranged to evaluate the persistent bleeding.

\section{Investigations}

An ultrasound pelvis done at 9 weeks postpartum to determine the cause of persistent spotting (Fig. 1,2), showed an endometrial thickness of $15 \mathrm{~mm}$. There was also a heterogeneous focal area measuring $2.0 \times 1.9 \times 1.3 \mathrm{~cm}$ at the Caesarean section scar, which was thought to represent a hematoma, although small amounts of retained products of conception could not be excluded. As the patient was clinically stable with no pyrexia and had minimal spotting, she was given another course of antibiotics and treated conservatively for possible retained product of conception. Her Pap smear was negative for malignancy. A high vaginal swab (HVS) showed normal vaginal flora with

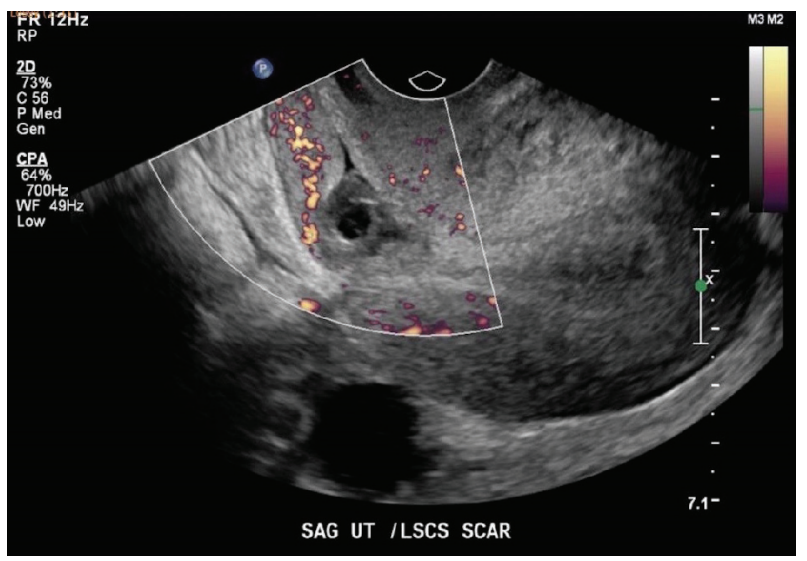

Figure 2. Ultrasound pelvis at 9 weeks postpartum showing the Caesarean scar haematoma.

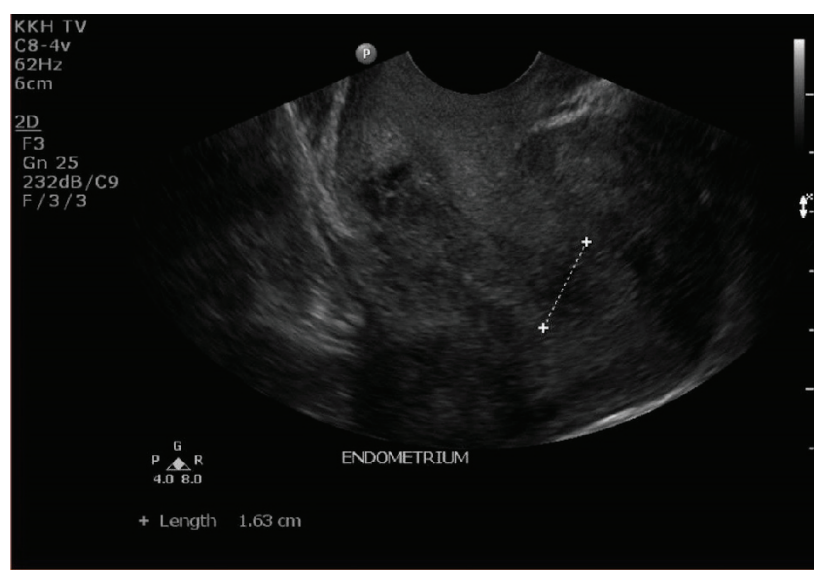

Figure 3. Ultrasound pelvis at 12 weeks postpartum showing a thickened endometrium of $16 \mathrm{~mm}$.

no evidence of an infective cause.

The lady was reviewed again in clinic 3 weeks later. She was still having persistent spotting on and off for now 3 months postpartum. Her urine pregnancy test was negative. An ultrasound pelvis was repeated (Fig. 3, 4). It showed a thickened endometrium of $16 \mathrm{~mm}$ with tiny cystic spaces and vascularity. The previously noted heterogeneous area at the Caesarean scar was noted to be slightly smaller now measuring $2.0 \times 1.2 \times$ $0.9 \mathrm{~cm}$.

In view of the ultrasound findings and the history of prolonged persistent spotting, she was listed for an elective hysteroscopy, dilation and curettage, which revealed a thickened polypoidal mass at the anterior uterine wall (Fig. 5). The histopathology of the curettings showed focal complex hyperplasia without atypia, with no trophoblastic cells or chorionic villi identified (Fig. 6).

The clinical history was revisited in detail revealing a history of dysfunctional uterine bleeding for many months prior to this pregnancy. Her other risk factors for endometrial hyperplasia include a body mass index (BMI) of 30 and a family history of endometrial cancer in her mother. However, she did not report any fertility issues and the pregnancy was a sponta-

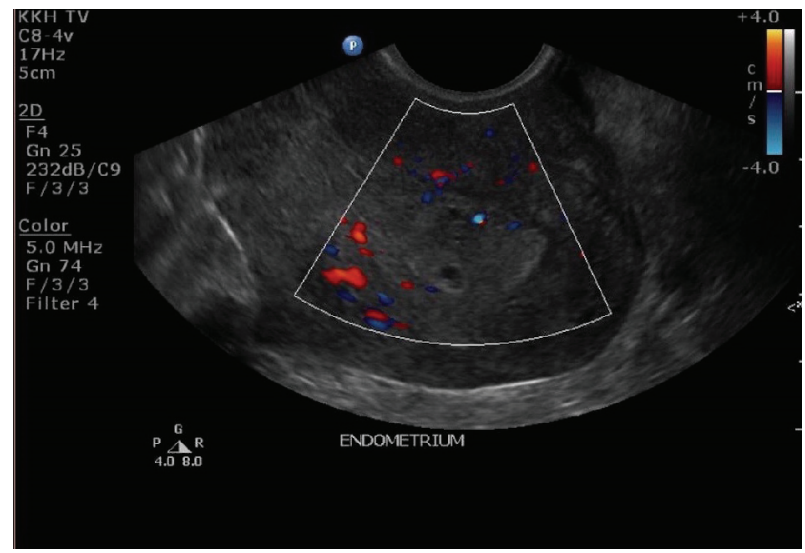

Figure 4. Ultrasound pelvis at 12 weeks postpartum showing a thickened endometrium with increased vascularity. 


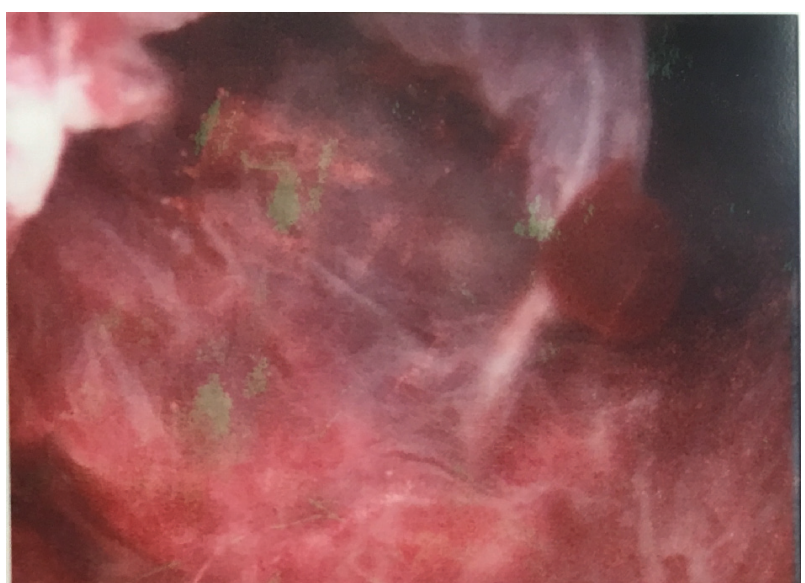

Figure 5. Hysteroscopy showing a thickened polypoidal mass at the posterior wall.

neous pregnancy.

\section{Treatment}

She was started on oral progestogens for treatment of endometrial hyperplasia after discussion with the gynecology-oncology multidisciplinary team.

\section{Outcome}

A repeat endometrial sampling done 4 months post therapy showed resolution of the endometrial hyperplasia. A Mirena intrauterine device was inserted as patient was also keen for contraception. She is presently on 6 monthly follow-ups at the specialist outpatient clinic.

\section{Discussion}

To the best of our knowledge, this is the first case report of postpartum endometrial hyperplasia in a non-stilbesterol exposed woman. The rarity of the diagnosis can be attributed to the underlying pathogenesis of endometrial hyperplasia. While it is well established that endometrial hyperplasia is caused by unopposed estrogen exposure, it is also known that pregnancy decreases this risk due to abundance of progesterone produced by the placenta. Another similar and rare histopathological differential diagnosis is localised endometrial proliferations of pregnancy (LEEP). The histopathological features include epithelial stratification, cribiforming, mitotic activity, bland nuclear cytology and prominent intraglandular calcifications. In one study [16], products of conceptions from 11 cases were initially diagnosed as atypical endometrial proliferations or focal endometrial carcinoma. However, follow-up of these patients showed no residual endometrial lesions. This suggests that the changes seen in the products of conception may be related to specific hormonal changes of early pregnancy. LEEP

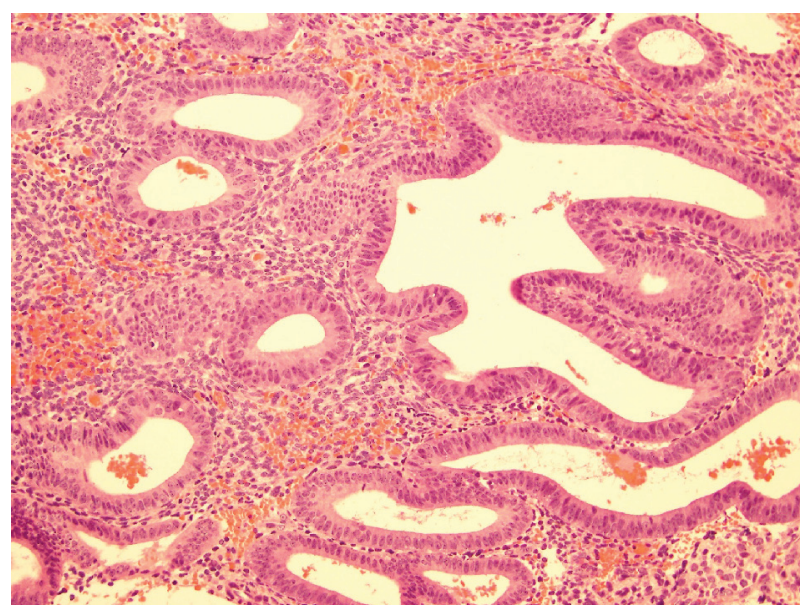

Figure 6. Histology slide showing complex hyperplasia without atypia.

is not the diagnosis in our patient, as her histological specimen was taken 3 months postpartum after delivery of a full term baby. We hypothesize that in this lady's case, the endometrial hyperplasia predated her pregnancy given her age and the history of abnormal uterine bleeding, and persisted postpartum as confirmed by the histopathology of endometrial curettings.

In clinical practice, the current treatment options for secondary PPH are usually not based on any evidence $[2,17]$. The management of PPH tends to be empirical, with the use of uterotonics, antibiotics or tranexamic acid, or a combination thereof. Nonetheless, most secondary PPH will be amenable to conservative management, which should be the primary option in hemodynamically stable patients. Any surgical management, which usually entails dilation and curettage, entails higher risk than medical management in the treatment of secondary PPH. In the study by Feigenberg et al [18], hysterectomy, blood transfusion, perforation of the uterus and systemic infection were more than twice as likely in women who had surgical rather than medical management of their secondary PPH.

The patient was initially managed conservatively as she was stable and her symptoms were mild. However, in view of persistence of symptoms and ultrasonographic evidence of an abnormal looking, thickened endometrium, surgical option was also discussed with the patient and resorted with consensus.

Another point of consideration in managing such cases is the patient's expectations and quality of life issues. Up to 9.5\% of women in an Aberdeen study [19] who had avoided resumption of sexual intercourse up to 8 weeks postpartum, mentioned "still bleeding" as a contributory factor. In our case report, our lady also reported to be feeling "bothered about the daily spotting as she required to wear a panty liner everyday".

Although, the diagnosis of endometrial hyperplasia as a cause of a secondary bleed in postpartum period is likely to be extremely rare, the incidence may indeed rise in future as more women embark on a pregnancy at a later age. This would fit in with a well established fact that endometrial hyperplasia is more common amongst older women in their $40 \mathrm{~s}$ due prolonged exposure to hormone estrogen [20]. It is also 
an important diagnosis to establish as endometrial hyperplasia in a pre-cancerous condition. The risk of progression depends on the histological subtype, which is low for women with non-atypical endometrial hyperplasia compared with women with cytologic atypia ( $<5 \%$ vs. approximately $30 \%$, respectively) $[21,22]$. Fortunately, our patient was diagnosed with non-atypical endometrial hyperplasia that was likely to have preceded her pregnancy. The high levels of progesterone in pregnancy may have prevented progression of the hyperplasia. Post diagnosis, she was successfully treated with progestins with regression of the hyperplasia. Previous reviews have also shown that non-atypical endometrial hyperplasia respond well to medical management with progestins. In a meta-analysis, the regression rates are reported to be $66.7 \%$ to $80.7 \%$ at 3 months to 64.6 to $91.0 \%$ at 1 year [23].

\section{Conflict of Interest}

The authors declare that there is no conflict of interest.

\section{References}

1. Boyd BK, Katz VL, Hansen WF. Delayed postpartum hemorrhage: a retrospective analysis. J Mat Fet Med. 1995;4:19-23.

2. Carroli G, Cuesta C, Abalos E, Gulmezoglu AM. Epidemiology of postpartum haemorrhage: a systematic review. Best Pract Res Clin Obstet Gynaecol. 2008;22(6):9991012.

3. King PA, Duthie SJ, Dong ZG, Ma HK. Secondary postpartum haemorrhage. Aust N Z J Obstet Gynaecol. 1989;29(4):394-398.

4. Hoveyda F, MacKenzie IZ. Secondary postpartum haemorrhage: incidence, morbidity and current management. BJOG. 2001;108(9):927-930.

5. Zubor P, Kajo K, Dokus K, Krivus S, Straka L, Bodova KB, Danko J. Recurrent secondary postpartum hemorrhages due to placental site vessel subinvolution and local uterine tissue coagulopathy. BMC Pregnancy Childbirth. 2014;14:80.

6. Yeniel AO, Ergenoglu AM, Akdemir A, Eminov E, Akercan F, Karadadas N. Massive secondary postpartum hemorrhage with uterine artery pseudoaneurysm after cesarean section. Case Rep Obstet Gynecol. 2013;2013:285846.

7. Kulkarni SS, Teoh WH, Sia AT, Nair S. Ruptured uterine artery pseudoaneurysm: an overlooked cause of late postpartum haemorrhage. Acta Anaesthesiol Belg. 2013;64(4):159-162.

8. Chitra TV, Panicker S. Pseudoaneurysm of uterine artery: a rare cause of secondary postpartum hemorrhage. J Obstet Gynaecol India. 2011;61(6):641-644.
9. Sengupta Dhar R, Misra R. Postpartum uterine wound dehiscence leading to secondary PPH: unusual sequelae. Case Rep Obstet Gynecol. 2012;2012:154685.

10. Chi C, Bapir M, Lee CA, Kadir R. Puerperal loss (lochia) in women with or without inherited bleeding disorders. Am J Obstet Gynecol. 2010;203(56):e1-5.

11. Weydert JA, Benda JA. Subinvolution of the placental site as an anatomic cause of postpartum uterine bleeding: a review. Arch Pathol Lab Med. 2006;130(10):15381542.

12. Wagner MS, Bedard MJ. Postpartum uterine wound dehiscence: a case report. J Obstet Gynaecol Can. 2006;28(8):713-715.

13. Dobson LS, Gillespie AM, Coleman Re, Hancock BW. The presentation and management of postpartum choriocarcinoma. Br J Cancer. 1999;79(9-10):1531-1533.

14. Leunen K, Amant F, Debiec-Rychter M, Croes R, Hagemeijer A, Schoenmakers EF, Vergote I. Endometrial stromal sarcoma presenting as postpartum haemorrhage: report of a case with a sole $\mathrm{t}(10 ; 17)(\mathrm{q} 22 ; \mathrm{p} 13)$ translocation. Gynecol Oncol. 2003;91(1):265-271.

15. Meissner WA, Sommers SC. Postpartum endometrial hyperplasia in diabetics treated with stilbestrol and progesterone. J Clin Endocrinol Metab. 1950;10(6):603-609.

16. Genest DR, Brodsky G, Lage JA. Localised endometrial proliferations associated with pregnancy: clinical and histopathological features of 11 cases. Hum Pathol. 1995; 26(11):1233-1240.

17. Alexander J, Thomas P, Sanghera J. Treatments of secondary postpartum haemorrhage (Review). Cochrane Database Syst Rev. 2002;(1):CD002867.

18. Feigenberg T, Eitan Y, Sela HY, Elchalal U, Ben-Meir A, Rojansky N. Surgical versus medical treatment for secondary post-partum hemorrhage. Acta Obstet Gynecol Scand. 2009;88(8):909-913.

19. Glazener CM. Sexual function after childbirth: women's experiences, persistent morbidity and lack of professional recognition. Br J Obstet Gynaecol. 1997;104(3):330-335.

20. Sherman ME, Sturgeon S, Brinton L, Kurman RJ. Endometrial cancer chemoprevention: implications of diverse pathways of carcinogenesis. J Cell Biochem Suppl. 1995;23:160-164.

21. Kurman RJ, Kaminski PF, Norris HJ. The behavior of endometrial hyperplasia. A long-term study of "untreated" hyperplasia in 170 patients. Cancer. 1985;56(2):403-412.

22. Lacey JV, Jr., Chia VM. Endometrial hyperplasia and the risk of progression to carcinoma. Maturitas. 2009;63(1):39-44.

23. Abu Hashim H, Ghayaty E, El Rakhawy M. Levonorgestrel-releasing intrauterine system vs oral progestins for non-atypical endometrial hyperplasia: a systematic review and metaanalysis of randomized trials. Am J Obstet Gynecol. 2015;213(4):469-478. 